\title{
Controlled Synthesis of $\mathrm{Tb}^{3+} / \mathrm{Eu}^{3+}$ Co-Doped $\mathrm{Gd}_{2} \mathrm{O}_{3}$ Phosphors with Enhanced Red Emission
}

\author{
Dong Zhu ${ }^{1,+}{ }^{,}$Jinkai $\mathrm{Li}^{1, *,+} \oplus$, Xiangyang Guo ${ }^{2}$, Qinggang $\mathrm{Li}^{1}{ }^{1}$, Hao $\mathrm{Wu}^{1, *} \mathbb{C}$, Lei Meng ${ }^{3, *}$ and \\ Zongming Liu ${ }^{1, *}$ \\ 1 School of Materials Science and Engineering, University of Jinan, Jinan, Shandong 250022, China; \\ mse_zhud@163.com (D.Z.); mse_liqg@ujn.edu.cn (Q.L.) \\ 2 Shandong Provincial Academy of Building Research, Jinan, Shandong 250031, China; gxy0818@163.com \\ 3 Department of Physics and Astronomy, KU Leuven, 3001 Leuven, Belgium \\ * Correspondence: mse_lijk@ujn.edu.cn (J.L.); mse_wuh@ujn.edu.cn (H.W.); lei.meng@kuleuven.be (L.M.); \\ ost_liuzongming@ujn.edu.cn (Z.L.); Tel.: +86-531-82765894 (J.L.) \\ + The two authors contributed equally to this paper.
}

Received: 29 December 2018; Accepted: 15 February 2019; Published: 20 February 2019

\begin{abstract}
Gd}_{0.93-x} \mathrm{~Tb}_{0.07} \mathrm{Eu}_{x}\right)_{2} \mathrm{O}_{3}(x=0-0.10)$ phosphors shows great potential for applications in the lighting and display areas. $\left(\mathrm{Gd}_{0.93-x} \mathrm{~Tb}_{0.07} \mathrm{Eu}_{x}\right)_{2} \mathrm{O}_{3}$ phosphors with controlled morphology were prepared by a hydrothermal method, followed by calcination at $1100^{\circ} \mathrm{C}$. XRD, FE-SEM, PL/PLE, luminescent decay analysis and thermal stability have been performed to investigate the $\mathrm{Eu}^{3+}$ content and the effects of hydrothermal conditions on the phase variation, microstructure, luminescent properties and energy transfer. Optimum excitation wavelength at $\sim 308 \mathrm{~nm}$ nanometer ascribed to the $4 f^{8}-4 f^{7} 5 d^{1}$ transition of $\mathrm{Tb}^{3+}$, the $\left(\mathrm{Gd}_{0.93-x} \mathrm{~Tb}_{0.07} \mathrm{Eu}_{x}\right)_{2} \mathrm{O}_{3}$ phosphors display both $\mathrm{Tb}^{3+}$ and $\mathrm{Eu}^{3+}$ emission with the strongest emission band at $\sim 611 \mathrm{~nm}$. For increasing $\mathrm{Eu}^{3+}$ content, the $\mathrm{Eu}^{3+}$ emission intensity increased as well while the $\mathrm{Tb}^{3+}$ emission intensity decreased owing to $\mathrm{Tb}^{3+} \rightarrow \mathrm{Eu}^{3+}$ energy transfer. The energy transfer efficiencies were calculated and the energy transfer mechanism was discussed in detail. The lifetime for both the $\mathrm{Eu}^{3+}$ and $\mathrm{Tb}^{3+}$ emission decreases with the $\mathrm{Eu}^{3+}$ addition, the former is due to the formation of resonant energy transfer net, and the latter is because of contribution by $\mathrm{Tb}^{3+} \rightarrow \mathrm{Eu}^{3+}$ energy transfer. The phosphor morphology can be controlled by adjusting the hydrothermal condition (reaction $\mathrm{pH}$ ), and the morphological influence to the luminescent properties (PL/PLE, decay lifetime, etc.) has been studied in detail.
\end{abstract}

Keywords: $\mathrm{Gd}_{2} \mathrm{O}_{3}: \mathrm{Tb}^{3+} / \mathrm{Eu}^{3+}$; hydrothermal method; luminescent properties; energy transfer

\section{Introduction}

The stable physical and chemical properties of $\mathrm{Gd}_{2} \mathrm{O}_{3}$ with cubic structure make it an important inorganic compound in luminescence applications. The $\mathrm{Gd}^{3+}$ in $\mathrm{Gd}_{2} \mathrm{O}_{3}$ could be easily substituted by an alternative rare earth activator ion $\left(\mathrm{Eu}^{3+}, \mathrm{Tb}^{3+}\right.$, etc. $)$ due to their similar ion radius $\left(\mathrm{Gd}^{3+}, \mathrm{Eu}^{3+}\right.$, and $\mathrm{Tb}^{3+}$ have ion radii of $1.053 \AA, 1.066 \AA$ and $1.040 \AA$ for coordination number 8) [1]. The $\mathrm{Eu}^{3+}$, $\mathrm{Tb}^{3+}$ and $\mathrm{Dy}^{3+}$ doped $\mathrm{Gd}_{2} \mathrm{O}_{3}$ matrix can emit vivid red, green and yellow colors, which in turn supports their use in the field of lighting and display [2-4].

The $\left(\mathrm{Gd}_{0.93-x} \mathrm{~Tb}_{0.07} \mathrm{Eu}_{x}\right)_{2} \mathrm{O}_{3}$ system was chosen in light of: (1) the luminescent properties of phosphor are greatly affected by the particle morphology and size, which relied on the synthesis route used. [5-7]. The hydrothermal method is usually selected to control the particle morphology and size [8-10], which is also applied in the preparation of $\mathrm{Gd}_{0.93-x} \mathrm{~Tb}_{0.07} \mathrm{Eu}_{x} \mathrm{O}_{3}$ systems in this work. Based on this, luminescent properties due to particle morphology and size were studied in detail; (2) due to higher ${ }^{6} \mathrm{I}_{\mathrm{J}}$ excited state of $\mathrm{Gd}^{3+}$ compared to ${ }^{5} \mathrm{D}_{3,4}$ and ${ }^{5} \mathrm{D}_{0,1}$ emission states of $\mathrm{Tb}^{3+}$ and 
$\mathrm{Eu}^{3+}$, the $\mathrm{Gd}^{3+}$ can sensitize the luminescence of $\mathrm{Tb}^{3+}$ and $\mathrm{Eu}^{3+}$ through $\mathrm{Gd}^{3+} \rightarrow \mathrm{Tb}^{3+}, \mathrm{Gd}^{3+} \rightarrow \mathrm{Eu}^{3+}$ energy transfer [11,12]. Meanwhile, $\mathrm{Tb}^{3+} \rightarrow \mathrm{Eu}^{3+}$ energy transfer reported in numerous works can also boost $\mathrm{Eu}^{3+}$ red emission [13], and the energy transfer of $\mathrm{Gd}^{3+} \rightarrow \mathrm{Tb}^{3+} \rightarrow \mathrm{Eu}^{3+}$ may also occur; (3) the lower electronegativity (1.20) of $\mathrm{Gd}^{3+}$ compared to $\mathrm{Y}^{3+}(1.22)$ and $\mathrm{Lu}^{3+}(1.27)$ may result in easier interconfigurational transition, which can induce new properties and further improve the red emission intensity. Better luminescence features of $\mathrm{Eu}^{3+}$ and $\mathrm{Tb}^{3+}$ in $\mathrm{Gd}_{2} \mathrm{O}_{3}$ than $\mathrm{Y}_{2} \mathrm{O}_{3}$ and $\mathrm{Lu}_{2} \mathrm{O}_{3}$ lattices may then be obtained, which is further validated by experiments in this work.

In this paper, a series of $\left(\mathrm{Gd}_{0.93-x} \mathrm{~Tb}_{0.07} \mathrm{Eu}_{x}\right)_{2} \mathrm{O}_{3}(x=0-0.10)$ phosphors were prepared through hydrothermal method, and the particle size and morphology were tuned by varying the reaction $\mathrm{pH}$ values. The phase structure, microstructure, luminescent properties, energy transfer efficiency and mechanism were analyzed by the combination of XRD, FE-SEM, PLE/PL and luminescent decay analysis. Moreover, morphology and size effect of the particle on the luminescent properties were investigated. In the sections that follow, we report in detail the synthesis, morphology/size controlled, luminescent traits, energy transfer and thermal stability of the phosphors.

\section{Results and Discussion}

The XRD patterns of precursors with different $\mathrm{Eu}^{3+}$ content are shown in Figure 1a. The diffraction peaks can be indexed as pure $\mathrm{Gd}(\mathrm{OH})_{3}$ (JCPDS NO.38-1042). All the samples show the same diffraction behavior, indicating that the $\mathrm{Eu}^{3+}$ addition does not significantly affect the crystal structure of the precursor. Figure $1 \mathrm{~b}$ displays the XRD patterns of $\left(\mathrm{Gd}_{0.93-x} \mathrm{~Tb}_{0.07} \mathrm{Eu}_{x}\right)_{2} \mathrm{O}_{3}(x=0-0.10)$ sintered at $1100{ }^{\circ} \mathrm{C}$ as a function of $\mathrm{Eu}^{3+}$ content (reaction $\mathrm{pH}=9.0$, hydrothermal temperature: $140{ }^{\circ} \mathrm{C}$ ). The diffraction peaks of the calcined products can be indexed as pure $\mathrm{Gd}_{2} \mathrm{O}_{3}$ phase (JCPDS NO. 43-1014) and no other phases are observed. All the samples show the same diffraction behavior indicating that the $\mathrm{Eu}^{3+}$ addition does not affect the crystal structure.
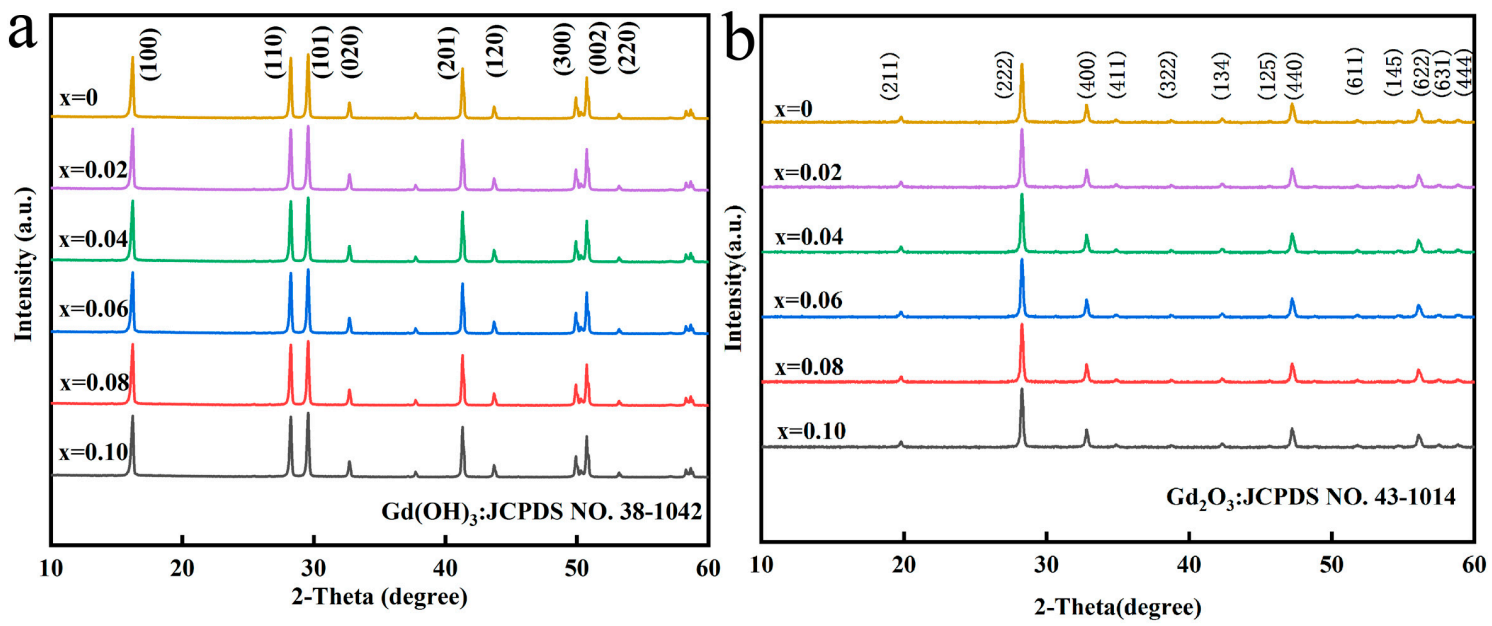

Figure 1. (a) is XRD spectra of precursors doped with different Eu contents, (b) is XRD spectra of $\left(\mathrm{Gd}_{0.93-x} \mathrm{~Tb}_{0.07} \mathrm{Eu}_{x}\right)_{2} \mathrm{O}_{3}(x=0-0.10)$ precursors calcined at $1100{ }^{\circ} \mathrm{C}$.

Figure 2 illustrates the FE-SEM images of the $\left(\mathrm{Gd}_{0.93-x} \mathrm{~Tb}_{0.07} \mathrm{Eu}_{x}\right)_{2} \mathrm{O}_{3}$ precursor sintered at $1100{ }^{\circ} \mathrm{C}$ with $x=0.04$ (a) and $x=0.1(\mathrm{~b})$, respectively (reaction $\mathrm{pH}=9.0$, hydrothermal temperature: $140{ }^{\circ} \mathrm{C}$ ). All the precursors display rod-resemble structures with diameters of $\sim 100 \mathrm{~nm}$ and lengths of $\sim 500 \mathrm{~nm}$. Comparison of the FE-SEM images in Figure $2 \mathrm{a}(x=0.04)$ and Figure $2 \mathrm{~b}(x=0.1)$ shows that the $\mathrm{Eu}^{3+}$ incorporation does not alter the particle morphology. The particles $\left(\mathrm{Gd}_{0.93-x} \mathrm{~Tb}_{0.07} \mathrm{Eu}_{x}\right)_{2} \mathrm{O}_{3}$ calcined at $1100{ }^{\circ} \mathrm{C}$ possess good dispersion and uniform morphology (Figure 2c, d), and the rod-like morphology of the precursor persists. The main variation was that the particles grew and the overall outline was clearer and more easily distinguished. 


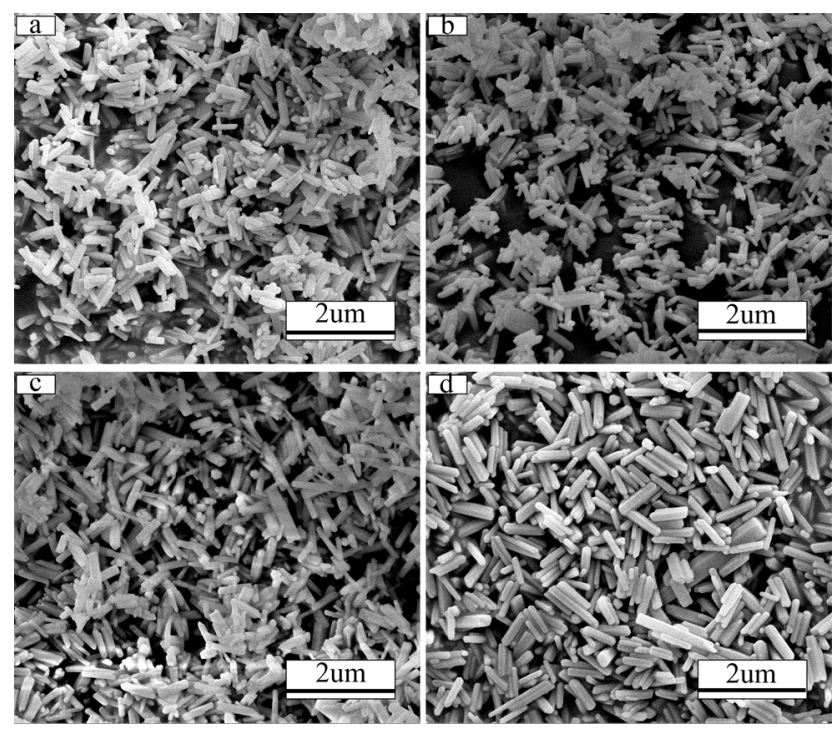

Figure 2. FE-SEM micrograph of the $\left(\mathrm{Gd}_{0.93-x} \mathrm{~Tb}_{0.07} \mathrm{Eu}_{x}\right)_{2} \mathrm{O}_{3}$ precursor with $x=0.04$ (a) and $x=0.1$

(b) and of the resultant product calcined at $100{ }^{\circ} \mathrm{C}, x=0.04$ (c) and $x=0.1$ (d).

Figure 3 shows FE-SEM micrographs of $\left(\mathrm{Gd}_{0.89} \mathrm{~Tb}_{0.07} \mathrm{Eu}_{0.04}\right)_{2} \mathrm{O}_{3}$ precursor synthesized at various $\mathrm{pH}$ values ( $\mathrm{pH} 8-12$, hydrothermal temperature: $140^{\circ} \mathrm{C}$ ). As we can see the particle morphology and size can be controlled by varying the $\mathrm{pH}$ value during synthesis. For the $\mathrm{pH}$ value of 8.0, the particles exhibit a tubular morphology (Figure 3a) with diameter of $\sim 200 \mathrm{~nm}$ and length of $\sim 800 \mathrm{~nm}$. In contrast, a $\mathrm{pH}$ value of 9.0 results in a rod-like particle morphology (Figure $3 \mathrm{~b}$ ). The formation of tubular and rod-shaped phosphors strongly depends on the mass transfer rate. At a low $\mathrm{pH}$ value of 8.0, the mass transfer speed of inner part is lower than the outer region, which leads to tube formation. As the $\mathrm{pH}$ increased to 9.0, the mass transfer speed between inner and outer region is comparable which leads to the formation of the rod morphology. While the $\mathrm{pH}$ value is further adjusted from 9.0 to 12.0, the precursor size with rod-like shape gradually decreased from diameter of $\sim 120 \mathrm{~nm}$ and length of $\sim 500 \mathrm{~nm}$ to $\sim 80 \mathrm{~nm}$ and $\sim 100 \mathrm{~nm}$, respectively. The reduction of the size is principally attributed to large nucleation density resulting from large $\mathrm{pH}$ value [14].
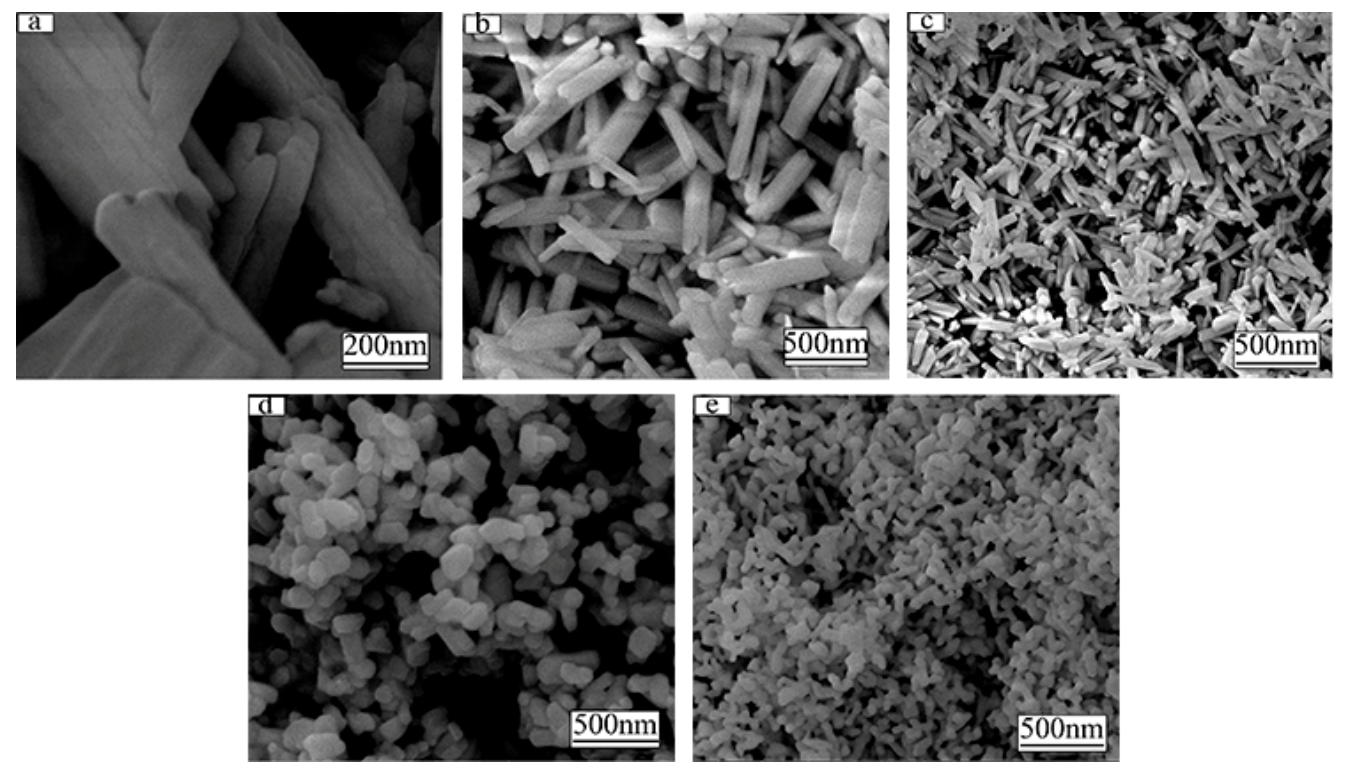

Figure 3. The FE-SEM morphologies of $\left(\mathrm{Gd}_{0.89} \mathrm{~Tb}_{0.07} \mathrm{Eu}_{0.04}\right)_{2} \mathrm{O}_{3}$ precursor synthesized with $\mathrm{pH}=8(\mathbf{a})$, 9 (b), 10 (c), 11 (d), 12 (e), respectively (hydrothermal temperature: $140{ }^{\circ} \mathrm{C}$ ). 
Figure 4 shows the excitation spectrum of the $\left(\mathrm{Gd}_{0.93-x} \mathrm{~Tb}_{0.07} \mathrm{Eu}_{x}\right)_{2} \mathrm{O}_{3}(x=0.02-0.1)$ samples (reaction $\mathrm{pH}=9.0$, hydrothermal temperature: $140^{\circ} \mathrm{C}$, calcined temperature: $1100{ }^{\circ} \mathrm{C}$ ) as a function of $\mathrm{Eu}^{3+}$ content at an emission wavelength of $542 \mathrm{~nm}\left(\mathrm{~Tb}^{3+}\right.$ emission, Figure $\left.4 \mathrm{a}\right)$ and $611 \mathrm{~nm}$ $\left(\mathrm{Eu}^{3+}\right.$ emission, Figure $\left.4 \mathrm{~b}\right)$, respectively. With monitoring at $542 \mathrm{~nm}$, the PLE spectra of the $\left(\mathrm{Gd}_{0.93-x} \mathrm{~Tb}_{0.07} \mathrm{Eu}_{x}\right)_{2} \mathrm{O}_{3}(x=0.02-0.1)$ system displays one strong and broad peak centered at $\sim 308 \mathrm{~nm}$ which is ascribed to the $4 f^{8}-4 f^{7} 5 d^{1}$ transition of $\mathrm{Tb}^{3+}$ [15], whereas by monitoring at $611 \mathrm{~nm}$ (Figure $4 \mathrm{~b}$ ), the PLE spectra of $\left(\mathrm{Gd}_{0.93-x} \mathrm{~Tb}_{0.07} \mathrm{Eu}_{x}\right)_{2} \mathrm{O}_{3}$ phosphors contain two excitation bands at $\sim 248 \mathrm{~nm}$ and $\sim 308 \mathrm{~nm}$ which is ascribed to the charge transfer band (CTB) of $\mathrm{Eu}^{3+}[16]$ and the $4 f^{8}-4 f^{7} 5 d^{1}$ transition of $\mathrm{Tb}^{3+}$, respectively. In addition, as we can see from the inline graph of $\mathrm{b}$, the CTB excitation peak of Eu ${ }^{3+}$ at $\sim 258 \mathrm{~nm}$ overlapped the characteristic transition ${ }^{8} \mathrm{~S}_{7 / 2^{-}}{ }^{6} \mathrm{I}_{\mathrm{J}}$ of $\mathrm{Gd}^{3+}$ implying the $\mathrm{Gd}^{3+} \rightarrow \mathrm{Eu}^{3+}$ energy transfer. The occurrence of $\mathrm{Gd}^{3+}$ and $\mathrm{Tb}^{3+}$ on the PLE spectra monitoring the $\mathrm{Eu}^{3+}$ emission provide clear information for energy transfer of the $\mathrm{Gd}^{3+} \rightarrow \mathrm{Eu}^{3+}$ and $\mathrm{Tb}^{3+} \rightarrow \mathrm{Eu}^{3+}[17,18]$. Therefore, not only the $\mathrm{Tb}^{3+}$ but also $\mathrm{Eu}^{3+}$ ions can be energized at $\sim 308 \mathrm{~nm}$. The PL spectra with $308 \mathrm{~nm}$ excitation are analyzed and presented in Figure 4c.
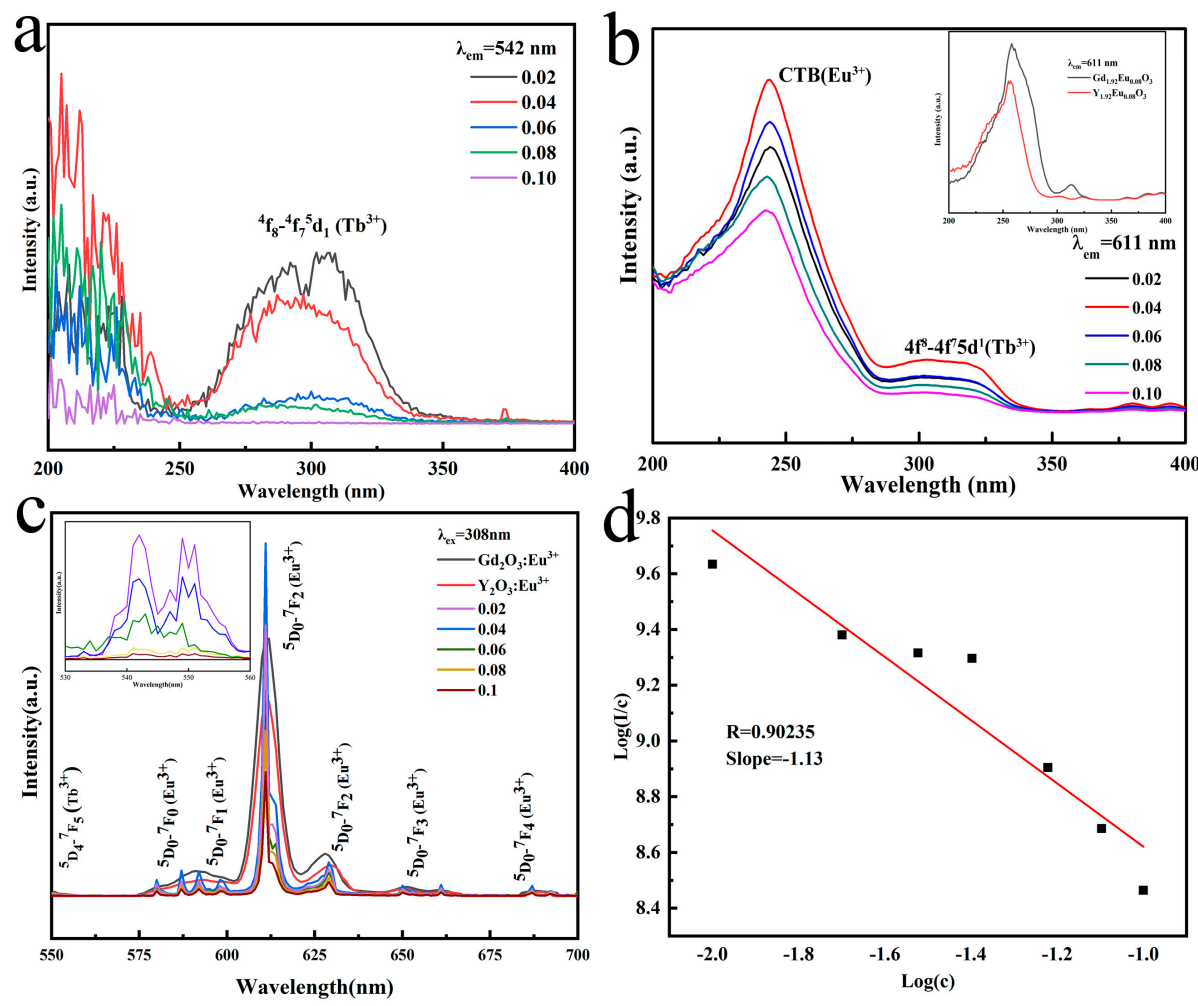

Figure 4. Figures (a) and (b) are the excitation spectra $\left(\mathbf{a}, \lambda_{e m}=542 \mathrm{~nm} ; \mathbf{b}, \lambda_{e m}=611 \mathrm{~nm}\right)$ of $\left(\mathrm{Gd}_{0.93-x} \mathrm{~Tb}_{0.07} \mathrm{Eu}_{x}\right)_{2} \mathrm{O}_{3}(x=0.02-0.1)$ phosphor calcined at $1100{ }^{\circ} \mathrm{C}$ as a function of $\mathrm{Eu}^{3+}$ content. The inset in (b) is the excitation spectrum contrast map of $\mathrm{Gd}_{1.92} \mathrm{Eu}_{0.08} \mathrm{O}_{3}$ and $\mathrm{Y}_{1.92} \mathrm{Eu}_{0.08} \mathrm{O}_{3}$ under $\lambda_{\text {em }}$ $=611 \mathrm{~nm}$. Figure $(\mathbf{c})$ shows the emission spectra $\left(\lambda_{\text {ex }}=308 \mathrm{~nm}\right)$ of $\left(\mathrm{Gd}_{0.93-x} \mathrm{~Tb}_{0.07} \mathrm{Eu}_{x}\right)_{2} \mathrm{O}_{3}(x=0.02-0.1)$, the $\left(\mathrm{Gd}_{0.96} \mathrm{Eu}_{0.04}\right)_{2} \mathrm{O}_{3}\left(\lambda_{e x}=258 \mathrm{~nm}\right)$ and $\left(\mathrm{Y}_{0.96} \mathrm{Eu}_{0.04}\right)_{2} \mathrm{O}_{3}\left(\lambda_{e x}=258 \mathrm{~nm}\right)$ were included for comparison. Inset is excitation spectra corresponding to $\mathrm{Gd}_{1.78} \mathrm{~Tb}_{0.14} \mathrm{Eu}_{0.08} \mathrm{O}_{3}, \mathrm{Gd}_{1.92} \mathrm{Eu}_{0.08} \mathrm{O}_{3}$ and $\mathrm{Y}_{1.92} \mathrm{Eu}_{0.08} \mathrm{O}_{3}$ with emission peak of $611 \mathrm{~nm}$. The inset in (c) is the enlarged graph of the $\mathrm{Tb}^{3+}$ emission peak. Figure (d) describes $\log (I / c)$ variation as related to $\log (c)$ for the $\left(\mathrm{Gd}_{0.93-x} \mathrm{~Tb}_{0.07} \mathrm{Eu}_{x}\right)_{2} \mathrm{O}_{3}$ phosphors calcined at $1100{ }^{\circ} \mathrm{C}$ (611 nm emission).

The PL spectra show the strongest emission band at $\sim 611 \mathrm{~nm}\left({ }^{5} \mathrm{D}_{0}{ }^{-}{ }^{7} \mathrm{~F}_{2}\right.$ transition of $\left.\mathrm{Eu}^{3+}\right)$ accompanied by other relatively weak emission bands at $\sim 542 \mathrm{~nm}, \sim 580 \mathrm{~nm}, \sim 593 \mathrm{~nm}, \sim 654 \mathrm{~nm}$ and $\sim 687 \mathrm{~nm}$ contributed to the ${ }^{5} \mathrm{D}_{4}-{ }^{7} \mathrm{~F}_{5}$ transition of $\mathrm{Tb}^{3+},{ }^{5} \mathrm{D}_{0}{ }^{7} \mathrm{~F}_{0}$ transition of $\mathrm{Eu}^{3+},{ }^{5} \mathrm{D}_{0}{ }^{7} \mathrm{~F}_{1}$ transition of $\mathrm{Eu}^{3+},{ }^{5} \mathrm{D}_{0}-{ }^{7} \mathrm{~F}_{3}$ transition of $\mathrm{Eu}^{3+}$, and ${ }^{5} \mathrm{D}_{0}{ }^{-7} \mathrm{~F}_{4}$ transition of $\mathrm{Eu}^{3+}$, respectively [19-22]. Both the appearance of the ${ }^{5} \mathrm{D}_{0}-{ }^{7} \mathrm{~F}_{0}$ transition of $\mathrm{Eu}^{3+}$ and the higher emission intensity of ${ }^{5} \mathrm{D}_{0}{ }^{-}{ }^{7} \mathrm{~F}_{2}$ 
transition of $\mathrm{Eu}^{3+}(\sim 611 \mathrm{~nm})$ compared with ${ }^{5} \mathrm{D}_{0}{ }^{-} \mathrm{F}_{1}$ transition of $\mathrm{Eu}^{3+}(\sim 593 \mathrm{~nm})$ imply that more $\mathrm{Eu}^{3+}$ occupies the relatively low symmetric lattice $\left(C_{2}\right)[23,24]$. The intensity of the emission at $611 \mathrm{~nm}$ increases with an increasing $\mathrm{Eu}^{3+}$ content (up to $x=0.04$ ), and then decreases because of the concentration quenching. Furthermore, the emission intensity of $\mathrm{Tb}^{3+}$ at $\sim 542 \mathrm{~nm}$ (the inset in Figure 4c) decreases resulting from the energy transfer of $\mathrm{Tb}^{3+} \rightarrow \mathrm{Eu}^{3+}$. Comparing the PL spectra of $\left(\mathrm{Gd}_{0.89} \mathrm{~Tb}_{0.07} \mathrm{Eu}_{0.04}\right)_{2} \mathrm{O}_{3},\left(\mathrm{Gd}_{0.96} \mathrm{Eu}_{0.04}\right)_{2} \mathrm{O}_{3}$ and $\left(\mathrm{Y}_{0.96} \mathrm{Eu}_{0.04}\right)_{2} \mathrm{O}_{3}$ (Figure 4c), the emission intensity is found in the order $\left(\mathrm{Gd}_{0.89} \mathrm{~Tb}_{0.07} \mathrm{Eu}_{0.04}\right)_{2} \mathrm{O}_{3}>\left(\mathrm{Gd}_{0.96} \mathrm{Eu}_{0.04}\right)_{2} \mathrm{O}_{3}>\left(\mathrm{Y}_{0.96} \mathrm{Eu}_{0.04}\right)_{2} \mathrm{O}_{3}$ due to the efficient $\mathrm{Gd}^{3+} \rightarrow \mathrm{Eu}^{3+}$ and $\mathrm{Tb}^{3+} \rightarrow \mathrm{Eu}^{3+}$ energy transfer.

The luminescence quenching type of $\mathrm{Eu}^{3+}$ in solid phosphors can be obtained through evaluating the parameter $s$ as indicated in Equation (1) [25-28]:

$$
\log \left(\frac{I}{c}\right)=\left(-\frac{s}{\mathrm{~d}}\right) \log (c)+\log f
$$

where I represents the $\mathrm{Eu}^{3+}$ emission intensity, $\mathrm{c}$ is the $\mathrm{Eu}^{3+}$ concentration, $\mathrm{d}=3$ for a regular sample, $f$ is a constant, and $s$ is the electric multipole index. When values of $3,6,8$ and 10 are assigned to $s$, different exchange interaction, dipole-dipole, dipole-quadrupole, and quadrupole-quadrupole electric interactions are obtained, respectively. The $\log (I / c)-\log (c)$ plot that corresponds to emission at $611 \mathrm{~nm}$ is shown in Figure $4 \mathrm{~d}$. The fitted slope $(-s / 3)$ was calculated to be -1.13 , thus $s=3.42(\sim 3)$ for the $\left(\mathrm{Gd}_{0.93-x} \mathrm{~Tb}_{0.07} \mathrm{Eu}_{x}\right)_{2} \mathrm{O}_{3}$ systems, indicating that concentration quenching is mostly caused by the energy transfer between $\mathrm{Eu}^{3+}$ ions [26,29].

The energy level diagram and energy transfer between $\mathrm{Gd}^{3+}, \mathrm{Tb}^{3+}$ and $\mathrm{Eu}^{3+}$ are shown in Figure 5. At $275 \mathrm{~nm}$ excitation, the electrons of $\mathrm{Gd}^{3+}$ are excited from the ${ }^{8} \mathrm{~S}_{7 / 2}$ to the ${ }^{6} \mathrm{I}_{\mathrm{J}}$ state, then relaxed to ${ }^{6} \mathrm{P}_{7 / 2}$ state. On the other hand, $\mathrm{UV}$ excitation makes the electrons of $\mathrm{Tb}^{3+}$ and $\mathrm{Eu}^{3+}$ shift from the ${ }^{7} \mathrm{~F}_{\mathrm{J}}(\mathrm{J}=3,4,5$, 6 for $\left.\mathrm{Tb}^{3+}\right)$ and ${ }^{7} \mathrm{~F}_{\mathrm{J}}\left(\mathrm{J}=0,1,2,3,4\right.$ for $\left.\mathrm{Eu}^{3+}\right)$ to the ${ }^{5} \mathrm{D}_{3}\left(\mathrm{~Tb}^{3+}\right)$ and ${ }^{5} \mathrm{D}_{1}\left(\mathrm{Eu}^{3+}\right)$ states followed by relaxation to ${ }^{5} \mathrm{D}_{4}\left(\mathrm{~Tb}^{3+}\right)$ and ${ }^{5} \mathrm{D}_{0}\left(\mathrm{Eu}^{3+}\right)$, respectively. Because the energy level of the ${ }^{6} \mathrm{P}_{7 / 2}$ state lies higher than the ${ }^{5} \mathrm{D}_{4}$ levels of $\mathrm{Tb}^{3+}$ and the ${ }^{5} \mathrm{D}_{0}$ level of $\mathrm{Eu}^{3+}$, the part energy of $\mathrm{Gd}^{3+}$ can be transferred to $\mathrm{Tb}^{3+}$ and $\mathrm{Eu}^{3+}[30]$, respectively. Meanwhile, energy transfer from $\mathrm{Tb}^{3+}$ to $\mathrm{Eu}^{3+}$ due to the higher energy level of ${ }^{5} \mathrm{D}_{4}\left(\mathrm{~Tb}^{3+}\right)$ compared to ${ }^{5} \mathrm{D}_{0}\left(\mathrm{Eu}^{3+}\right)$ can happen. The electrons of ${ }^{5} \mathrm{D}_{4}\left(\mathrm{~Tb}^{3+}\right)$ and ${ }^{5} \mathrm{D}_{0}\left(\mathrm{Eu}^{3+}\right)$ states jump back to the ground state ${ }^{7} \mathrm{~F}_{\mathrm{J}}$, thereby producing green $\left(\mathrm{Tb}^{3+}\right)$ and red $\left(\mathrm{Eu}^{3+}\right)$ emissions [31].

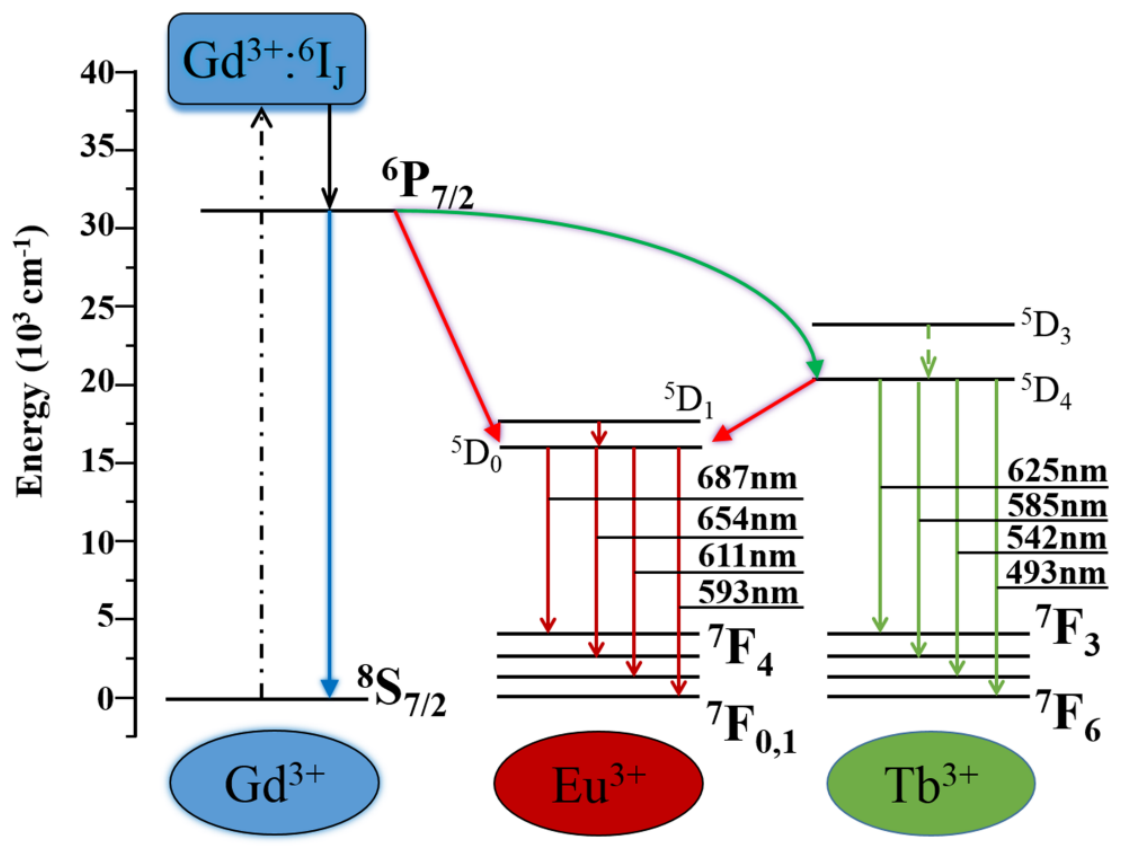

Figure 5. Energy level diagram and energy transfer mechanism of $\mathrm{Gd}^{3+}, \mathrm{Tb}^{3+}$ and $\mathrm{Eu}^{3+}$ in $\left(\mathrm{Gd}_{0.93-x} \mathrm{~Tb}_{0.07} \mathrm{Eu}_{x}\right)_{2} \mathrm{O}_{3}(x=0.02-0.1)$ phosphor. 
In order to calculate the energy transfer efficiency between $\mathrm{Tb}^{3+}$ and $\mathrm{Eu}^{3+}$, the luminescence decay behavior of $\mathrm{Tb}^{3+}$ at $542 \mathrm{~nm}$ was investigated using the $x=0.04$ and the results are shown in Figure 6a. As we can see that the kinetics of decay follow a single exponential decay behavior:

$$
I=A \exp \left(-\frac{t}{\tau_{R}}\right)+B
$$

where $I$ refers to luminescence intensity, t represents the decay time $\tau_{R}$ denotes the lifetime and $A$ and $B$ are the constants [32]. The fitted result yields $A=8424.79 \pm 821.77$ (au), $B=100.24 \pm 24.60$ (au) and $\tau_{R}=0.16 \pm 0.01 \mathrm{~ms}$. The lifetime values for $\mathrm{Tb}^{3+}$ shown in the inset of Figure 6a decrease gradually with increasing $\mathrm{Eu}^{3+}$ content because of energy transfer $\mathrm{Tb}^{3+} \rightarrow \mathrm{Eu}^{3+}$. with transfer efficiency $\left(\eta_{E T}\right)$ being obtained by evaluating the lifetime of $\mathrm{Tb}^{3+}$ with $\left(\tau_{S}\right)$ and without $\left(\tau_{S 0}\right) \mathrm{Eu}^{3+}$ doping through Equation (3) [33]:

$$
\eta_{E T}=1-\frac{\tau_{S}}{\tau_{S 0}}
$$
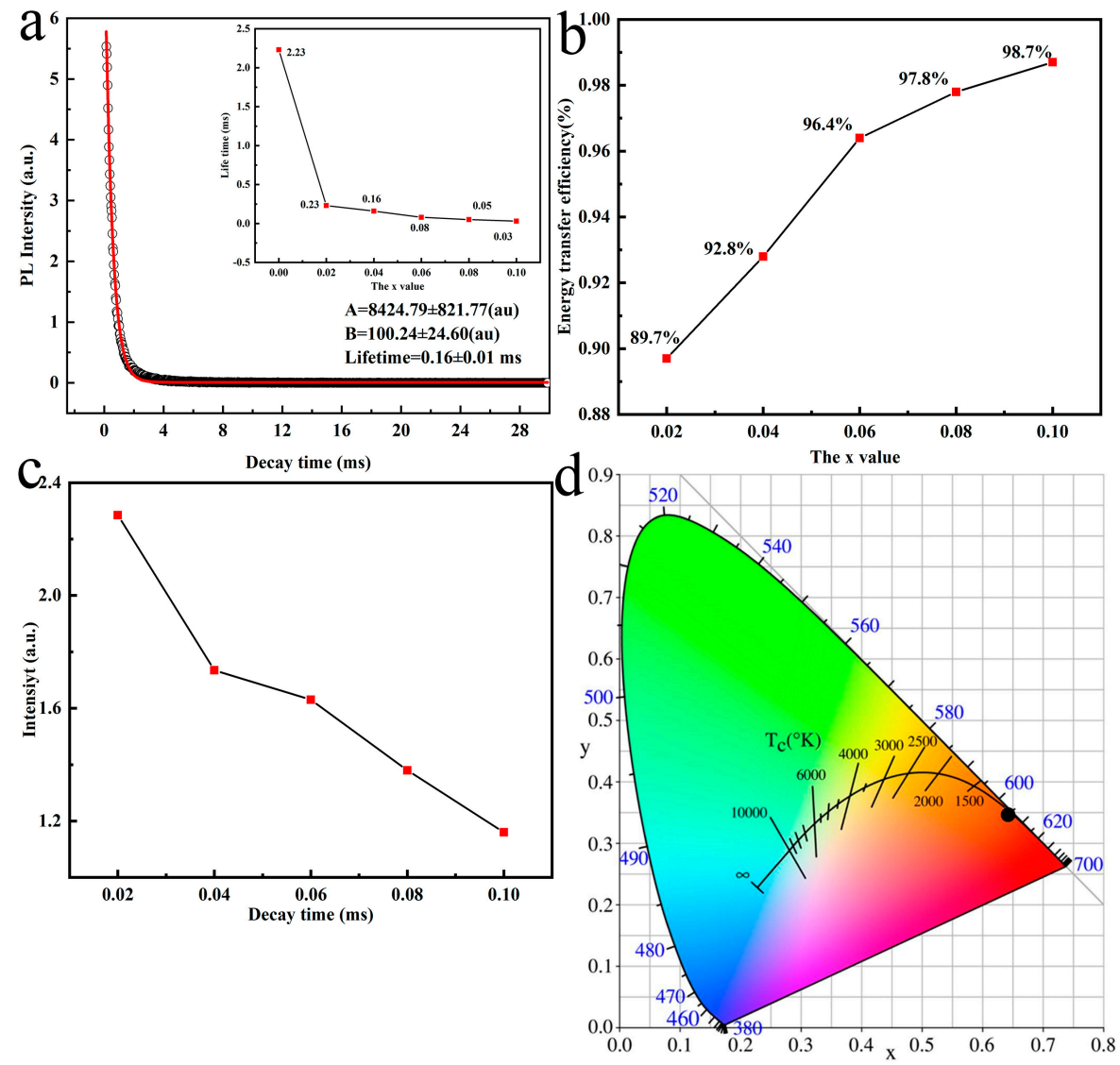

Figure 6. (a) The decay behavior $\left(\mathrm{Gd}_{0.89} \mathrm{~Tb}_{0.07} \mathrm{Eu}_{0.04}\right)_{2} \mathrm{O}_{3}$ (reaction $\mathrm{pH}=9.0$, hydrothermal temperature: $140{ }^{\circ} \mathrm{C}$, calcination temperature: $\left.110^{\circ} \mathrm{C}\right)$ for the $542 \mathrm{~nm}$ emission of $\mathrm{Tb}^{3+}\left(\lambda_{e x}=308 \mathrm{~nm}\right)$. The inset is the lifetime variation against $\mathrm{Eu}^{3+}$ content; (b) the calculated energy transfer efficiency between $\mathrm{Tb}^{3+}$ and $\mathrm{Eu}^{3+}$ as function of $\mathrm{Eu}^{3+}$ content; (c) the lifetime value of $\mathrm{Eu}^{3+}$ for $611 \mathrm{~nm}$ emission with the change of $\mathrm{Eu}^{3+}$ content $\left(\lambda_{e x}=308 \mathrm{~nm}\right)$; (d) the CIE chromaticity diagram for the emission of $\left(\mathrm{Gd}_{0.89} \mathrm{~Tb}_{0.07} \mathrm{Eu}_{0.04}\right)_{2} \mathrm{O}_{3}$ phosphors under $308 \mathrm{~nm}$ excitation.

The results of energy transfer efficiency calculation are shown in Figure $6 \mathrm{~b}$. As can be seen, $\eta_{E T}$ has a positive correlation with $\mathrm{Eu}^{3+}$ concentration where increased $\mathrm{Eu}^{3+}$ content, from $x=0.02$ to $x=$ 0.10 , leads to gradually enhanced efficiency of energy transfer, from $89.7 \%$ to $98.7 \%$. By consequence, the sensitizer of $\mathrm{Tb}^{3+}$ plays a critical part in the luminescence emission of $\mathrm{Eu}^{3+}$ with large $\eta_{E T}$ value 
predominantly generating from substantial overlapping of spectra between the ${ }^{5} \mathrm{D}_{4} \rightarrow{ }^{7} \mathrm{~F}_{\mathrm{J}}$ emissions of $\mathrm{Tb}^{3+}$ and the ${ }^{7} \mathrm{~F}_{0,1} \rightarrow{ }^{5} \mathrm{D}_{0,1}$ absorption of $\mathrm{Eu}^{3+}$ [34]. Figure 6c shows the lifetime value of $\mathrm{Eu}^{3+}$ for $611 \mathrm{~nm}$ emission relative to $\mathrm{Eu}^{3+}$ content, through where we can see that the lifetime of $\mathrm{Eu}^{3+}$ decreases from 2.24 to $1.19 \mathrm{~ms}$ with $\mathrm{Eu}^{3+}$ addition from $x=0.02$ to $x=0.10$, resulting from the formation of a resonant energy transfer net among the activators. Figure $6 \mathrm{~d}$ depicts the CIE chromaticity coordinates for $\left(\mathrm{Gd}_{0.89} \mathrm{~Tb}_{0.07} \mathrm{Eu}_{0.04}\right)_{2} \mathrm{O}_{3}$ phosphors with $308 \mathrm{~nm}$ excitation. The CIE chromaticity coordinate and color temperature are determined to be $(\sim 0.64, \sim 0.35)$ and $\sim 2439 \mathrm{~K}$, respectively, as a result the phosphors gives a vivid red color.

The energy transfer mechanism between $\mathrm{Tb}^{3+} \rightarrow \mathrm{Eu}^{3+}$ can be analyzed according to Dexter' and Reisfeld's theory $[35,36]$, and the explanation is given as in the equations below:

$$
\begin{aligned}
& \ln \frac{I_{S 0}}{I_{S}} \propto C \\
& \frac{I_{S 0}}{I_{S}} \propto C^{\frac{n}{3}}
\end{aligned}
$$

where $C$ is the summed concentration of doped ions $\mathrm{Tb}^{3+}$ and $\mathrm{Eu}^{3+} ; I_{S 0}$ and $I_{S}$ are the emission intensities of $\mathrm{Tb}^{3+}$ for $542 \mathrm{~nm}$ emission with and without $\mathrm{Eu}^{3+} ; \ln I_{s 0} / I_{s}-C$ corresponds to exchange interactions, and $\ln I_{s 0} / I_{s}-C^{n / 3}$ for $n=6,8,10$ represent the dipole-dipole, dipole-quadrupole and quadrupole-quadrupole electric interactions, respectively. The plots of $\ln I_{s 0} / I_{s}-C$ and $\ln I_{s 0} / I_{s}-C^{n / 3}$ are illustrated in Figure 7. By comparing the fitted factor values (R), the best linear relationship was found for $n=10$, which clearly shows energy transfer from $\mathrm{Tb}^{3+} \rightarrow \mathrm{Eu}^{3+}$ in the $\left(\mathrm{Gd}_{1-x} \mathrm{~Tb}_{0.07} \mathrm{Eu}_{x}\right)_{2} \mathrm{O}_{3}$ phosphor is dominated by quadrupole-quadrupole electric interactions [27].
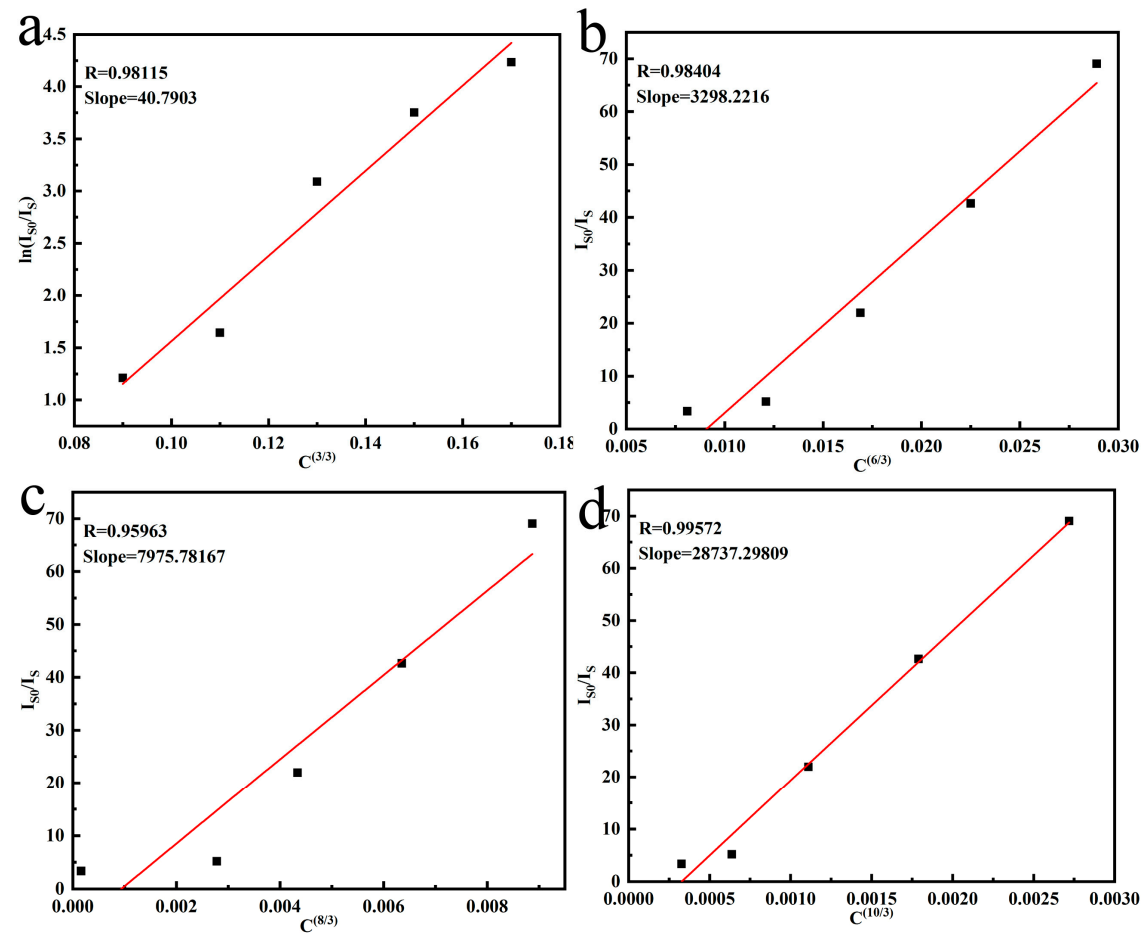

Figure 7. The relationship $\ln I_{S 0} / I_{S}-C$ (a) and $I_{S 0} / I_{S}-C^{n / 3}$ of $\left(\mathrm{Gd}_{0.89} \mathrm{~Tb}_{0.07} \mathrm{Eu}_{0.04}\right)_{2} \mathrm{O}_{3}$ (reaction $\mathrm{pH}=9.0$, hydrothermal temperature: $140{ }^{\circ} \mathrm{C}$, calcination temperature: $\left.1100{ }^{\circ} \mathrm{C}\right)$ with $n=6(\mathbf{b}), n=8(\mathrm{c})$, $n=10(\mathbf{d})$, respectively.

Considering that the change of hydrothermal $\mathrm{pH}$ values can alter the particle morphology (Figure 3), and the shape/size has a significant effect on the luminescent properties, we investigated the PL spectra of the $\left(\mathrm{Gd}_{0.89} \mathrm{~Tb}_{0.07} \mathrm{Eu}_{0.04}\right)_{2} \mathrm{O}_{3}$ sample as a function of $\mathrm{pH}$ value $(\mathrm{pH}=8-12$, Figure $8 \mathrm{a}$, 
hydrothermal temperature: $140^{\circ} \mathrm{C}$, calcined temperature: $1100^{\circ} \mathrm{C}$ ). From Figure 8 , we can conclude that the $\mathrm{pH}$ value variation has no influence to the shape of the emission peak, however it affects the emission intensity of $\mathrm{Eu}^{3+}$ dramatically. The emission intensity first decreases with the increasing $\mathrm{pH}$ till $\mathrm{pH}=9.0$. Thereafter it increases as the $\mathrm{pH}$ further increases up to 12.0. When the $\mathrm{pH}$ varies from 8.0 to 9.0 , and the particle morphology changes from tubular to rods, with the latter presenting directional growth as described in Figure $3 b-$ e. The phosphors with rod-like morphology could decrease the electric dipole transition probabilities of $\mathrm{Eu}^{3+}$, therefore decreasing the luminescence intensity [28]. For $\mathrm{pH}$ changing from 9.0 to 12.0, the particle dimension progressively decreases while the surface area gradually increases. As a result, the luminescent center number on the particle surface increases leading to an improved intensity of emission.
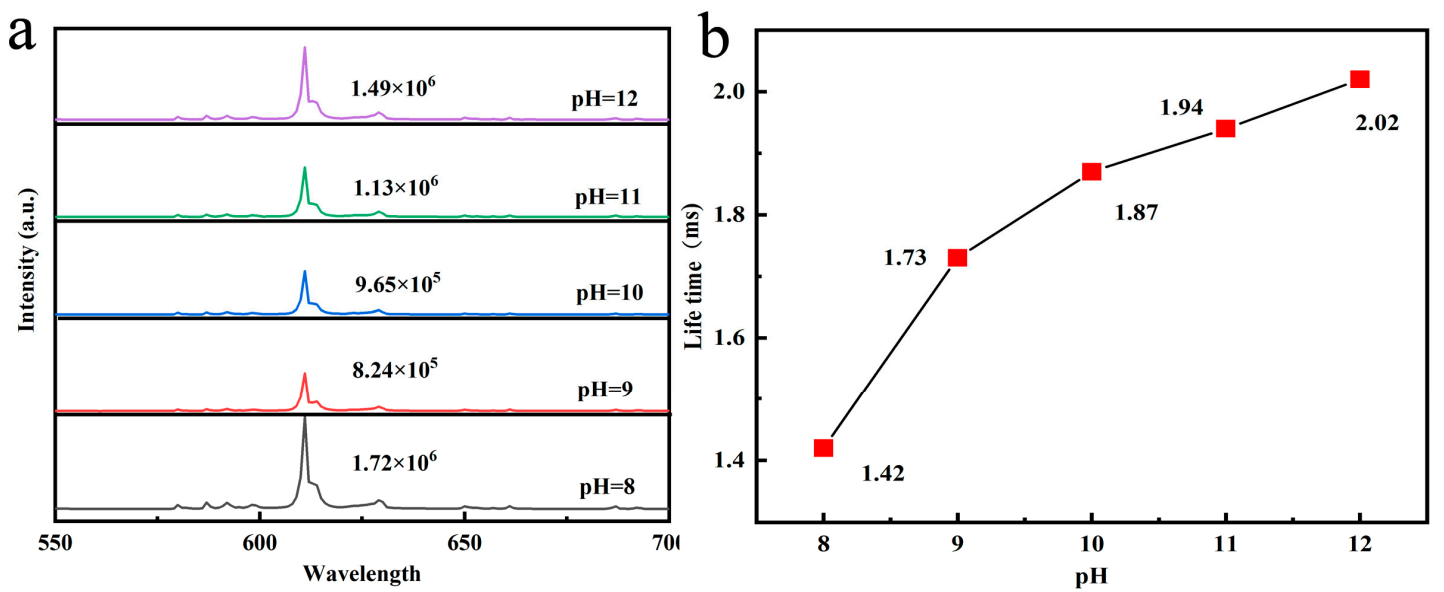

Figure 8. (a) emission spectrum of $\left(\mathrm{Gd}_{0.89} \mathrm{~Tb}_{0.07} \mathrm{Eu}_{0.04}\right)_{2} \mathrm{O}_{3}$ synthesized with different $\mathrm{pH}$ values marked in the figure $\left(\lambda_{e x}=308 \mathrm{~nm}\right)$; (b) lifetime values of $\left(\mathrm{Gd}_{0.89} \mathrm{~Tb}_{0.07} \mathrm{Eu}_{0.04}\right)_{2} \mathrm{O}_{3}$ for the $611 \mathrm{~nm}$ emission of $\mathrm{Eu}^{3+}$ as a function of $\mathrm{pH}$ value.

Figure $8 \mathrm{~b}$ displays the lifetime values of the $611 \mathrm{~nm}$ emission with different synthesis $\mathrm{pH}$ values. The lifetime increases from 1.42 to $2.02 \mathrm{~ms}$ with the $\mathrm{pH}$ increasing from 8.0 to 12.0. The extended lifetime can be expressed via Equation (6) [25,37]:

$$
\tau_{R} \sim \frac{1}{f(E D)} \frac{\lambda_{0}^{2}}{\left[\frac{1}{3}\left(n_{e f f}{ }^{2}+2\right)\right]^{2} n_{e f f}}
$$

where $f(E D)$ and $\lambda_{0}$ are represent the dipole transition oscillator strength and the wavelength in vacuum, respectively. $n_{\text {eff }}$ is the effective refractive index which is influenced by the particle size and decreases for smaller particles when applied to intermediately-sized particles as in this work. Thus, the $n_{\text {eff }}$ decreased at a larger given $\mathrm{pH}$ value, and a longer lifetime was obtained. The influences of the defects of lattice on luminescent lifetime, nevertheless, can in no way be totally excluded. Deep traps are believed to be capable of arresting electrons temporarily, thus leading to a longer lifetime.

The thermal stability for phosphor materials is an important parameter for its potential application. The influences of temperature variation to the intensity of emission was investigated in the range of 298-523 $\mathrm{K}$ using $\left(\mathrm{Gd}_{0.89} \mathrm{~Tb}_{0.07} \mathrm{Eu}_{0.04}\right)_{2} \mathrm{O}_{3}$ as an example (reaction $\mathrm{pH}=8.0$, hydrothermal temperature: $140{ }^{\circ} \mathrm{C}$, calcination temperature: $1100{ }^{\circ} \mathrm{C}$ ), and the activation energy was also calculated in this work. Owing to the thermal quenching, the emission intensity of $\left(\mathrm{Gd}_{0.89} \mathrm{~Tb}_{0.07} \mathrm{Eu}_{0.04}\right)_{2} \mathrm{O}_{3}$ phosphor decreased with increasing temperature (Figure 9a). The temperature resulted thermal quenching can be explained using Arrhenius equation [27,38]:

$$
\ln \left(\frac{I_{0}}{I}-1\right)=\ln A-\frac{E_{a}}{k T}
$$


where $E_{a}$ is the activation energy, $T$ denotes temperature, $A$ is a constant and $k$ refers to the Boltzmann constant. $I_{0}$ is the emission intensity at room temperature while $I$ corresponds to the emission intensity at the related operating temperature. The variation of $\ln \left[\left(I_{0}-I\right) / I\right]$ in terms of $1 / k T$ for the thermal quenching is shown in Figure $9 \mathrm{~b}$. The slope of the fitting curve is -0.211 , which corresponds to the $E_{a}$ value of $0.211 \mathrm{eV}$ being almost the same as the $0.212 \mathrm{eV}$ value for the $\mathrm{Gd}_{2} \mathrm{O}_{3}: \mathrm{Dy}^{3+} / \mathrm{Eu}^{3+}$ system $[39,40]$. The larger activation energy means that the synthesized phosphor has a more stable thermal stability compared to other reported phosphors and can be potentially used in lighting and display areas [41].
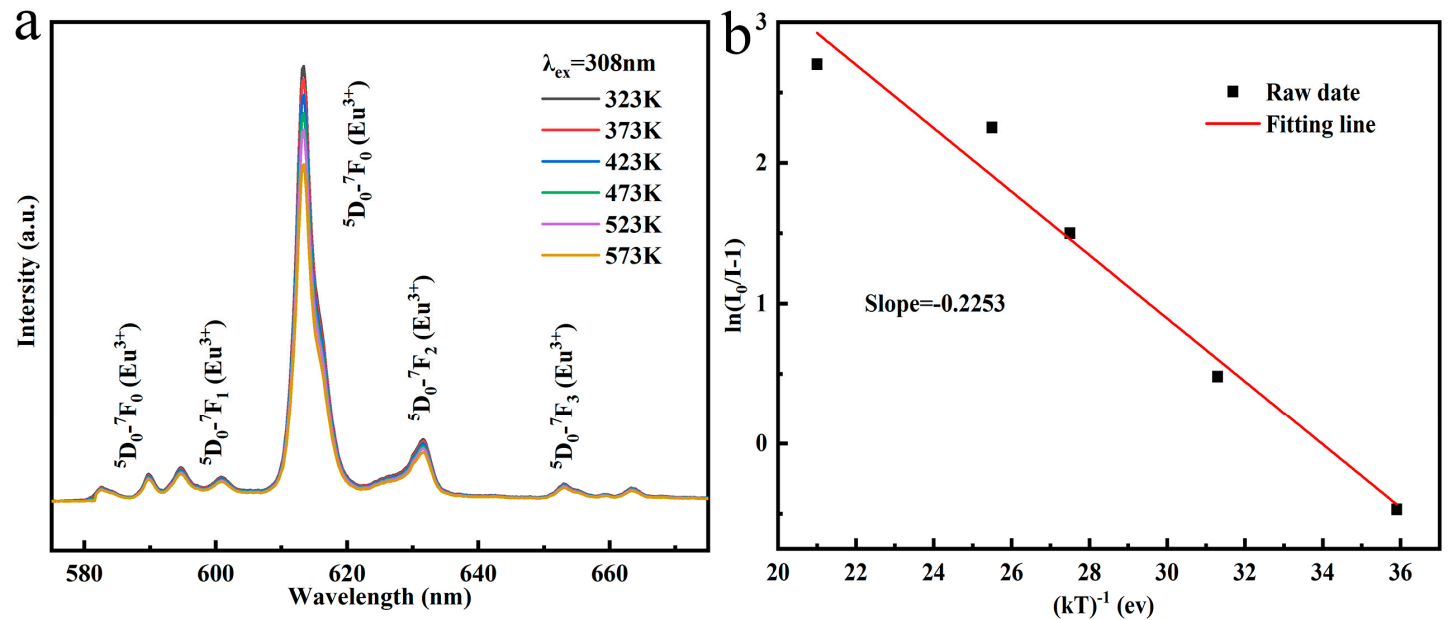

Figure 9. Temperature-dependent PL intensity is shown in (a), and the relationship between $\ln \left(\mathrm{I}_{0} / \mathrm{I}-1\right)$ and $1 / \mathrm{kT}$ is displayed in (b).

\section{Summary}

Pure-phase $\left(\mathrm{Gd}_{0.93-x} \mathrm{~Tb}_{0.07} \mathrm{Eu}_{x}\right)_{2} \mathrm{O}_{3}(x=0.02-0.1)$ phosphors with controlled morphology were synthesized by hydrothermal method, followed by calcination. The combined technologies of XRD, FE-SEM, PLE/PL, decay behavior and thermal stability have been applied to analyze the products. The analysis results can be summarized as follows:

(1) Increasing $\mathrm{Eu}^{3+}$ content does not change the particle morphology, but both the particle shape and size can be controlled by tuning the $\mathrm{pH}$ value used in the hydrothermal synthesis. The particle morphology varies from tubular to rod-like when the $\mathrm{pH}$ value increases from 8.0 to 9.0. The rod-like particle size decreases with the $\mathrm{pH}$ value when increased from 9.0 to 12.0;

(2) $\left(\mathrm{Gd}_{0.93-x} \mathrm{~Tb}_{0.07} \mathrm{Eu}_{x}\right)_{2} \mathrm{O}_{3}$ phosphors exhibit a vivid red emission with a CIE chromaticity coordinate and color temperature of $(\sim 0.64, \sim 0.35)$ and $\sim 2439 \mathrm{~K}$, respectively. The quenching concentration was $x=0.04$, and determined to be due to energy transfer between $\mathrm{Eu}^{3+}$. Comparing to the $\left(\mathrm{Gd}_{0.96} \mathrm{Eu}_{0.04}\right)_{2} \mathrm{O}_{3}$ and $\left(\mathrm{Y}_{0.96} \mathrm{Eu}_{0.04}\right)_{2} \mathrm{O}_{3}$ oxides, the $\left(\mathrm{Gd}_{0.89} \mathrm{~Tb}_{0.07} \mathrm{Eu}_{0.04}\right)_{2} \mathrm{O}_{3}$ possesses better luminescent properties due to $\mathrm{Tb}^{3+} \rightarrow \mathrm{Eu}^{3+}, \mathrm{Gd}^{3+} \rightarrow \mathrm{Eu}^{3+}$ energy transfer;

(3) The influence of particle shape or size on the luminescence features, e.g. PLE/PL, lifetime, of resultant phosphors was investigated. The related energy transfer efficiency, mechanism, process and thermal stability were also analyzed in detail.

\section{Experimental Procedures}

The chemical reagents used in the synthesis include rare earth oxides $\left(\mathrm{Gd}_{2} \mathrm{O}_{3}, \mathrm{~Tb}_{4} \mathrm{O}_{7}\right.$, and $\mathrm{Eu}_{2} \mathrm{O}_{3}$, 99.99\% pure, Jining Zhongkai New Type Material Science Co. Ltd, Jining, China), ammonia $\left(\mathrm{NH}_{3} \cdot \mathrm{H}_{2} \mathrm{O}\right.$, analytical grade $25 \mathrm{wt} \%)$ and nitric acid $\left(\mathrm{HNO}_{3}\right.$, analytical grade $\left.68 \mathrm{wt} \%\right)$. Both acids were purchased from Sinopharm Chemical Reagent Co. Ltd. (Shanghai, China). All reagents were utilized as starting material with no additional purification. 
The whole synthesis process is shown in Figure 10. The rare earth nitrates $\mathrm{RE}\left(\mathrm{NO}_{3}\right)_{3}(\mathrm{RE}=\mathrm{Gd}$, $\mathrm{Tb}, \mathrm{Eu}$ ) were provided via dissolving the corresponding oxides, $\mathrm{Gd}_{2} \mathrm{O}_{3}, \mathrm{~Tb}_{4} \mathrm{O}_{7}$ and $\mathrm{Eu}_{2} \mathrm{O}_{3}$, in hot nitric acid. $\mathrm{RE}\left(\mathrm{NO}_{3}\right)_{3}$ was mixed as mother salt and stirred for 30 minutes according to the stoichiometric ratio $\left(\mathrm{Gd}_{0.93-x} \mathrm{~Tb}_{0.07} \mathrm{Eu}_{x}\right)_{2} \mathrm{O}_{3}$. Ammonia was used to adjust the $\mathrm{pH}$ of the mother salt, and the resulting turbid liquid was aged for $30 \mathrm{~min}$. The turbid liquids were transferred to an autoclave and heated in an oven for $24 \mathrm{~h}$. Upon completion of the reaction, the suspension was cooled to room temperature, followed by centrifugation and repeated washing using distilled water and alcohol to give a precipitate. The wet precipitate was dried at $180{ }^{\circ} \mathrm{C}$ for $24 \mathrm{~h}$ in air. The precursors were firstly decomposed at $600{ }^{\circ} \mathrm{C}$ for $4 \mathrm{~h}$ in the air, and then calcined at $1100{ }^{\circ} \mathrm{C}$ for $4 \mathrm{~h}$ in $\mathrm{Ar} / \mathrm{H}_{2}\left(5 \mathrm{vol} . \% \mathrm{H}_{2}\right)$ gas mixture to obtain the resultant oxides. The $\mathrm{Eu}^{3+}$ content $(x=0-0.10)$ and reaction $\mathrm{pH}(\mathrm{pH}=8.0-12.0)$ were varied to study their effects on the particle morphology and size.

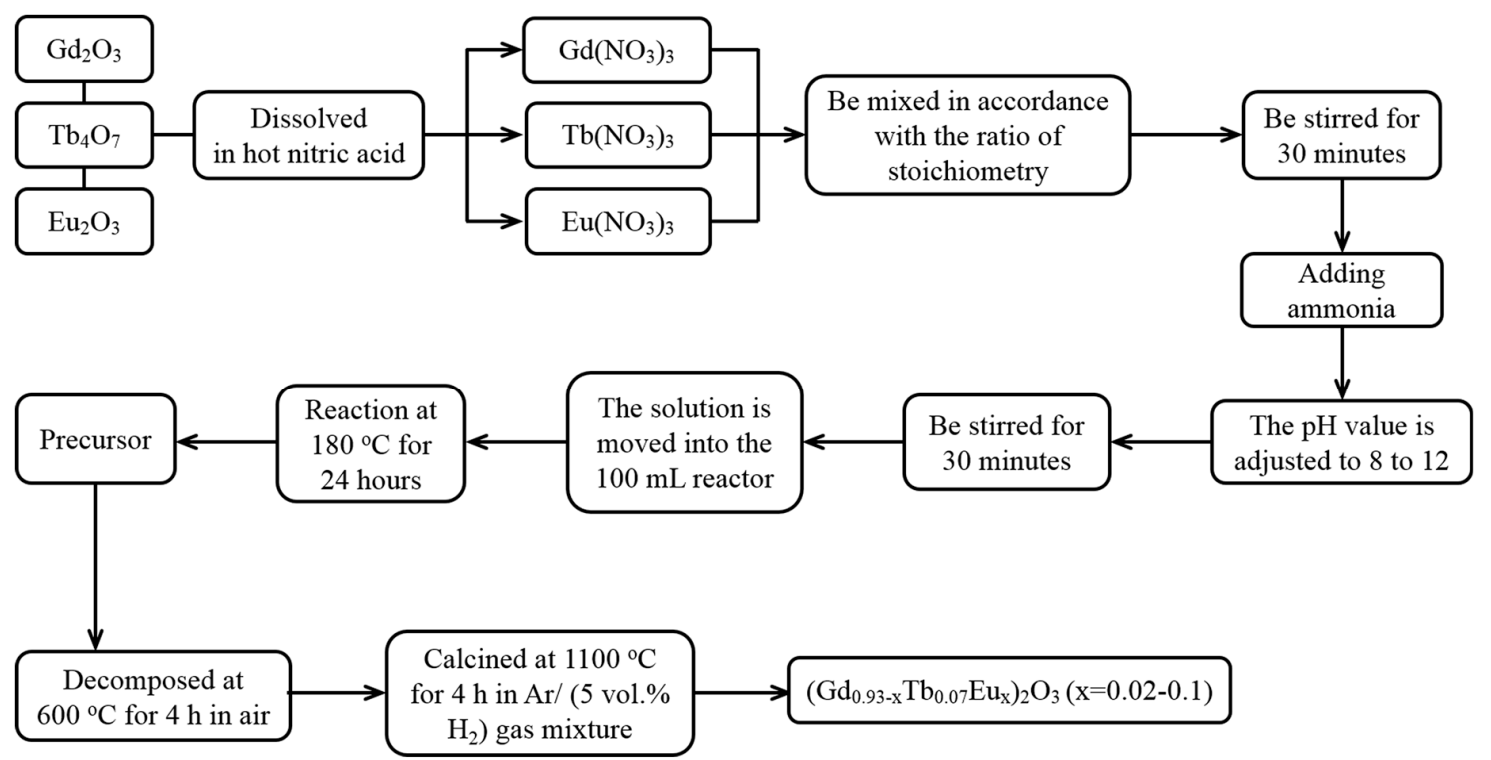

Figure 10. The synthesis scheme of $\left(\mathrm{Gd}_{0.93-x} \mathrm{~Tb}_{0.07} \mathrm{Eu}_{x}\right)_{2} \mathrm{O}_{3}$ phosphors.

Phosphor phases were identified by X-ray diffractometry (XRD, Model PW3040/60, PANALYTICAL B.V, Almelo, The Netherlands) with nickel-filtered $\mathrm{CuK} \alpha$ radiation and a $4^{\circ} 2 \theta / \mathrm{min}$ scanning speed. Particle morphological distribution was studied by field-emission scanning electron microscopy (FE-SEM, Model JSM-7001F, JEOL, Tokyo, Japan). Photoluminescence excitation (PLE) and photoluminescence (PL) spectra of the phosphors were collected by a FP-6500 fluorospectrophotometer (JASCO, Tokyo, Japan) at room temperature, which has an integrating sphere (Model ISF-513, JASCO) of diameter of $60 \mathrm{~mm}$ and an excitation source, Xe lamp, $150 \mathrm{~W}$. The decay kinetic of $\mathrm{Eu}^{3+}$ and $\mathrm{Tb}^{3+}$ emission was acquired at room temperature. By exciting the phosphor powder at a chosen wavelength, the emission intensity was detected as to the elapsed time immediately after the excitation light was blocked by a shutter.

Author Contributions: For research articles with several authors, a short paragraph specifying their individual contributions must be provided. The following statements should be used "conceptualization, D.Z.; methodology, X.G.; software, Q.L.; validation, H.W.; formal analysis, X.G.; investigation, D.Z.; resources, Z.L.; data curation, H.W.; writing —original draft preparation, D.Z.; writing—review and editing, J.L.; visualization, L.M. and J.L.; supervision, J.L. and Z.L.; project administration, Q.L.; funding acquisition, Z.L.

Funding: This work was supported in part by the National Natural Science Foundation of China (No. 51402125), China Postdoctoral Science Foundation (No. 2017M612175), the Research Fund for the Doctoral Program of University of Jinan (No. XBS1447), the Natural Science Foundation of University of Jinan (No. XKY1515), the Science Foundation for Post Doctorate Research from the University of Jinan (No. XBH1607), the Special Fund of Postdoctoral innovation project in Shandong province (No. 201603061).

Conflicts of Interest: The authors declare no conflict of interest. 


\section{References}

1. Shannon, R.D. Revised effective ionic radii and systematic studies of interatomic distances in halides and chalcogenides. Acta Cryst. 1976, A32, 751-767. [CrossRef]

2. Li, J.H.; Liang, Q.Y.; Hong, J.Y.; Yan, J.; Dolgov, L.; Meng, Y.Y.; Xu, Y.Q.; Shi, J.X.; Wu, M.M. White light-emitting and enhanced color stability in a single component host. ACS Appl. Mater. Inter. 2018, 10, 18066-18072. [CrossRef] [PubMed]

3. Li, Y.; Geceviciusa, M.; Qiu, J.R. Long persistent phosphors-from fundamentals to applications. Chem. Soc. Rev. 2016, 45, 2090-2136. [CrossRef] [PubMed]

4. Zhang, Y.; Jie, W.J.; Chen, P.; Liu, W.W.; Hao, J.H. Ferroelectric and piezoelectric effects on the optical process in advanced materials and devices. Adv. Mater. 2018, 34, 1707007. [CrossRef] [PubMed]

5. Chhabra, V.; Pillai, V.; Mishra, B.K.; Morrone, A.; Shah, D.O. Synthesis, characterization, and properties of microemulsion-mediated nanophase TiO2 particles. Langmuir 1995, 11, 3307-3311. [CrossRef]

6. Xuan, T.T.; Yang, X.F.; Lou, S.Q.; Huang, J.J.; Liu, Y.; Yu, J.B.; Li, H.L.; Wong, K.L.; Wang, C.X.; Wang, J. Highly stable $\mathrm{CsPBr}_{3}$ quantum dots coated with alkyl phosphate for white light-emitting diodes. Nanoscale 2017, 9, 15286-15290. [CrossRef]

7. Zou, R.; Gong, S.M.; Shi, J.P.; Jiao, J.; Wong, K.L.; Zhang, H.W.; Wang, J.; Su, Q. Magnetic-NIR persistent luminescent dual-modal ZGOCS@MSNs@ $\mathrm{Gd}_{2} \mathrm{O}_{3}$ core-shell nanoprobes for In vivo imaging. Chem. Mater. 2017, 29, 3938-3946. [CrossRef]

8. Pang, X.C.; He, Y.J.; Jung, J.; Lin, Z.Q. 1D nanocrystals with precisely controlled dimensions, compositions, and architectures. Science 2016, 353, 1268-1272. [CrossRef]

9. Li, J.H.; Zhang, Z.H.; Li, X.H.; Xu, Y.Q.; Ai, Y.Y.; Yan, J.; Shi, J.X.; Wu, M.M. Luminescence properties and energy transfer of $\mathrm{YGa}_{1.5} \mathrm{Al}_{1.5}\left(\mathrm{BO}_{3}\right)_{4}: \mathrm{Tb}^{3+}, \mathrm{Eu}^{3+}$ as a multi-colour emitting phosphor for WLEDs. J. Mater. Chem. C 2017, 25, 6294-6299. [CrossRef]

10. Li, J.H.; Yan, J.; Wen, D.W.; Khan, W.U.; Shi, J.X.; Wu, M.M.; Su, Q.; Tanner, P.A. Advanced Red Phosphors for White Light-emitting Diodes. J. Mater. Chem. C 2016, 37, 8611-8623. [CrossRef]

11. Liu, L.; Fu, G.R.; Li, B.N.; Lu, X.Q.; Wong, W.K.; Jones, R.A. Single-component $\mathrm{Eu}^{3+}-\mathrm{Tb}^{3+}-\mathrm{Gd}^{3+}$-grafted polymer with ultra-high color rendering index white-light emission. Rsc. Adv. 2017, 11, 6762-6771. [CrossRef]

12. Anh, T.K.; Ngoc, T.; Nga, P.T.; Bich, V.T.; Long, P. Energy transfer between $\mathrm{Tb}^{3+}$ and $\mathrm{Eu}^{3+}$ in $\mathrm{Y}_{2} \mathrm{O}_{3}$ crystals. J. Lumin. 1988, 39, 215-221.

13. Reddy, G.V.L.; Moorthy, L.R.; Chengaiah, T.; Jamalaiah, B.C. Multi-color emission tunability and energy transfer studies of $\mathrm{YAl}_{3}\left(\mathrm{BO}_{3}\right)_{4}: \mathrm{Eu}^{3+} / \mathrm{Tb}^{3+}$ phosphors. Ceram. Int. 2014, 40, 3399-3410. [CrossRef]

14. Li, G.R.; Lu, X.H.; Zhao, W.X.; Su, C.Y.; Tong, Y.X. Controllable electrochemical synthesis of Ce $\mathrm{e}^{4+}$-doped $\mathrm{ZnO}$ nanostructures from nanotubes to nanorods and nanocages. Cryst. Growth Des. 2008, 8, 1276-1281. [CrossRef]

15. Wu, X.L.; Li, J.G.; Li, J.K.; Zhu, Q.; Li, X.D.; Sun, X.D.; Sakka, Y. Layered rare-earth hydroxide and oxide nanoplates of the $\mathrm{Y} / \mathrm{Tb} /$ Eu system: Phase-controlled processing, structure characterization and color-tunable photoluminescence via selective excitation and efficient energy transfer. Sci. Technol. Adv. Mater. 2013, 14, 015006. [CrossRef] [PubMed]

16. Zhang, Y.; Zhang, X.J.; Zhang, H.R.; Zheng, L.L.; Zeng, Y.; Lin, Y.; Liu, Y.L.; Lei, B.F. Tunable emission from green to red in the $\mathrm{GdSr}_{2} \mathrm{AlO}_{5}: \mathrm{Tb}^{3+}, \mathrm{Eu}^{3+}$ phosphor via efficient energy transfer, nanophosphors. Rsc Adv. 2018, 8, 3530-3535. [CrossRef]

17. Liu, L.L.; Wang, Q.; Gao, C.J.; Chen, H.; Liu, W.S.; Tang, Y. Dramatically enhanced luminescence of layered terbium hydroxides as induced by the synergistic effect of $\mathrm{Gd}^{3+}$ and organic sensitizers. J. Phys. Chem. C 2014, 118, 14511-14520. [CrossRef]

18. Jain, A.; Hirata, G.A. Photoluminescence, size and morphology of red-emitting $\mathrm{Gd}_{2} \mathrm{O}_{3}: \mathrm{Eu}^{3+}$, nanophosphor synthesized by various methods. Ceram. Int. 2016, 42, 6428-6435. [CrossRef]

19. Xin, F.X.; Zhao, S.L.; Xu, S.Q.; Huang, L.H.; Jia, G.H.; Deng, D.G.; Wang, H.P. Structure and luminescence properties of $\mathrm{Eu} / \mathrm{Tb}$ codoped oxyfluoride glass ceramics containing $\mathrm{Sr}_{2} \mathrm{GdF}_{7}$ nanocrystals. Opt. Mater. 2011, 34, 85-88. [CrossRef]

20. Li, S.; Guo, N.; Liang, Q.M.; Ding, Y.; Zhou, H.T.; Ouyang, R.Z.; Lü, W. Energy transfer and color tunable emission in $\mathrm{Tb}^{3+}, \mathrm{Eu}^{3+}$ co-doped $\mathrm{Sr}_{3} \mathrm{LaNa}\left(\mathrm{PO}_{4}\right)_{3} \mathrm{~F}$ phosphors. Spectrochim Acta A 2018, 190, $246-252$. [CrossRef] 
21. Li, J.; Chen, L.; Zhang, J.H.; Hao, Z.D.; Luo, Y.S.; Zhang, L.G. Photoluminescence properties of a novel red-emitting phosphor $\mathrm{Eu}^{3+}$ activated scandium molybdate for white light emitting diodes. Mater. Res. Bull. 2016, 83, 290-293. [CrossRef]

22. Li, F.H.; Liu, H.; Wei, S.L.; Sun, W.; Yu, L.X. Photoluminescent properties of $\mathrm{Eu}^{3+}$ and $\mathrm{Tb}^{3+}$ codoped $\mathrm{Gd}_{2} \mathrm{O}_{3}$ nanowires and bulk materials. J. Rare Earth. 2013, 111, 1063-1068. [CrossRef]

23. Gai, S.L.; Yang, P.P.; Wang, D.; Li, C.X.; Niu, N.; He, F.; Li, X.B. Monodisperse $\mathrm{Gd}_{2} \mathrm{O}_{3}$ : $\mathrm{Ln}\left(\mathrm{Ln}^{2} \mathrm{Eu}^{3+}\right.$, $\mathrm{Tb}^{3+}, \mathrm{Dy}^{3+}, \mathrm{Sm}^{3+}, \mathrm{Yb}^{3+} / \mathrm{Er}^{3+}, \mathrm{Yb}^{3+} / \mathrm{Tm}^{3+}$, and $\mathrm{Yb}^{3+} / \mathrm{Ho}^{3+}$ ) nanocrystals with tunable size and multicolor luminescent properties. Cryst. Eng. Comm. 2011, 13, 5480-5487. [CrossRef]

24. Bi, H.F.; Li, X. Self-assembled columnar structure $\mathrm{Gd}_{2} \mathrm{O}_{3}: \mathrm{Eu}^{3+}$ : Solvothermal synthesis and luminescence properties. Integr. Ferroelectr. 2012, 135, 119-124. [CrossRef]

25. Blasse, G. Energy transfer in oxidic phosphors. Philips Res. Rep. 1969, 24, 131-144. [CrossRef]

26. Chen, Q.; Li, J.K.; Wang, W.Z. Synthesis and luminescence properties of $\mathrm{Tb}^{3+} / \mathrm{Eu}^{3+}$ co-doped $\mathrm{GdAlO}_{3}$ phosphors with enhanced red emission. J. Rare Earths 2018, 36, 924-930. [CrossRef]

27. Dexter, D.L.; Schulman, J.H. Theory of concentration quenching in inorganic phosphors. J. Chem. Phys. 1954, 22, 1063-1070. [CrossRef]

28. Dexter, D.L. A theory of sensitized luminescence in solids. J. Chem. Phys. 1953, 21, 836-850. [CrossRef]

29. Reisfeld, R.; Greenberg, E.; Velapoldi, R.; Barnett, B. Luminescence quantum efficiency of Gd and Tb in borate glasses and the mechanism of energy transfer between them. J. Chem. Phys. 1972, 56, 1698-1705. [CrossRef]

30. Zhu, Q.; Li, J.G.; Li, X.D.; Sun, X.D. Selective processing, structural characterization, and photoluminescence behaviors of single crystalline $\left(\mathrm{Gd}_{1-\mathrm{x}} \mathrm{Eu}_{\mathrm{x}}\right)_{2} \mathrm{O}_{3}$ nanorods and nanotubes. Curr. Nanosci. 2010, 6, 496-504. [CrossRef]

31. Dai, Q.L.; Song, H.W.; Wang, M.Y.; Bai, X.; Dong, B.; Qin, R.F.; Qu, X.S.; Zhang, H. Size and concentration effects on the photoluminescence of $\mathrm{La}_{2} \mathrm{O}_{2} \mathrm{~S}: \mathrm{Eu}^{3+}$ nanocrystals. J. Phys. Chem. C 2008, 112, 19399-19404. [CrossRef]

32. Li, Y.; Hong, G. Synthesis and luminescence properties of nanocrystalline $\mathrm{Gd}_{2} \mathrm{O}_{3}: \mathrm{Eu}^{3+}$ by combustion process. J. Lumin. 2007, 124, 297-301. [CrossRef]

33. Mutelet, B.; Perriat, P.; Ledoux, G.; Amans, D.; Lux, F.; Tillement, O.; Billotey, C.; Janier, M.; Villiers, C.; Bazzi, R.; et al. Suppression of luminescence quenching at the nanometer scale in $\mathrm{Gd}_{2} \mathrm{O}_{3}$ doped with Eu ${ }^{3+}$ or $\mathrm{Tb}^{3+}$ : Systematic comparison between nanometric and macroscopic samples of life-time, quantum yield, radiative and non-radiative decay rates. J. Appl. Phys. 2011, 110, 4317-4326. [CrossRef]

34. Jia, G.; Liu, K.; Zheng, Y.H.; Song, Y.H.; Yang, M.; You, H.P. Highly uniform $\mathrm{Gd}(\mathrm{OH})_{3}$ and $\mathrm{Gd}_{2} \mathrm{O}_{3}: \mathrm{Eu}^{3+}$ nanotubes: Facile synthesis and luminescence properties. J. Phy. Chem. C 2009, 113, 6050-6055. [CrossRef]

35. Devaraju, M.K.; Yin, S.; Sato, T. Solvothermal synthesis, controlled morphology and optical properties of $\mathrm{Y}_{2} \mathrm{O}_{3}: \mathrm{Eu}^{3+}$ nanocrystals. J. Cryst. Growth 2009, 311, 580-584. [CrossRef]

36. Ramírez, A.D.J.M.; Murillo, A.G.; Romo, F.D.J.C.; Salgado, J.R.; Luyer, C.L.; Chadeyron, G.; Boyer, D.; Palmerin, J.M. Preparation and studies of $\mathrm{Eu}^{3+}$ and $\mathrm{Tb}^{3+}$ co-doped $\mathrm{Gd}_{2} \mathrm{O}_{3}$ and $\mathrm{Y}_{2} \mathrm{O}_{3}$ sol-gel scintillating films. Thin Solid Films 2009, 517, 6753-6758. [CrossRef]

37. Zhang, K.; Holloway, T.; Pradhan, A.K.; Cui, Y.; Bhattacharya, P.; Burger, A.; Kar, A.; Patra, A. Synthesis and optical properties of $\mathrm{Eu}^{3+}$ and $\mathrm{Tb}^{3+}$ doped $\mathrm{Gd}_{2} \mathrm{O}_{3}$ nanotubes. Sci. Adv. Mate. 2012, 4, 649-655. [CrossRef]

38. Xu, Z.H.; Yang, J.; Hou, Z.Y.; Li, C.X.; Zhang, C.M.; Huang, S.S.; Lin, J. Hydrothermal synthesis and luminescent properties of $\mathrm{Y}_{2} \mathrm{O}_{3}: \mathrm{Tb}^{3+}$ and $\mathrm{Gd}_{2} \mathrm{O}_{3}: \mathrm{Tb}^{3+}$ microrods. Mater. Res. Bull. 2009, 44, 1850-1857. [CrossRef]

39. Meltzer, R.S.; Feofilov, S.P.; Tissue, B.; Yuan, H.B. Dependence of fluorescence lifetimes of $\mathrm{Y}_{2} \mathrm{O}_{3}: \mathrm{Eu}^{3+}$, nanoparticles on the surrounding medium. Phys. Rev. B 1999, 60, 14012-14015. [CrossRef]

40. Liu, B.; Li, J.K.; Duan, G.B.; Li, Q.G.; Liu, Z.M. The synthesis and luminescent properties of morphology-controlled $\mathrm{Gd}_{2} \mathrm{O}_{3}: \mathrm{Dy}^{3+} / \mathrm{Eu}^{3+}$ phosphors with enhanced red emission via energy transfer. J. Lumin. 2019, 206, 348-358. [CrossRef]

41. Yang, J.; Quan, Z.W.; Kong, D.Y.; Liu, X.M.; Lin, J. $\mathrm{Y}_{2} \mathrm{O}_{3}: \mathrm{Eu}^{3+}$ microspheres: Solvothermal synthesis and luminescence properties. Cryst. Growth Des. 2007, 7, 730-735. [CrossRef]

Sample Availability: Samples of the compounds are not available from authors. 